\title{
Navigation of Stents across Communicating Arteries for Aneurysm Embolization
}

\author{
Muhammad Ejaz Ahmed, Cheemun Lum, Howard Lesiuk, Daniela Iancu, \\ Marlise dos Santos
}

\begin{abstract}
Introduction: Endovascular coiling of aneurysms crossing the Circle of Willis has been described in small case series. The technical challenges in manipulating a stent across the Circle of Willis lie in negotiating difficult angles and small arteries. We present our experience with treating aneurysms by stent assistance in which the Circle of Willis was crossed to facilitate optimal stent deployment. Materials and methods: We retrospectively reviewed the cases in our institution from January 2009 to June 2012 in which the Circle of Willis was traversed to facilitate optimal stent deployment. We measured the diameter of the communicating arteries traversed, caliber of the target arteries in which the stent was deployed and the most acute angle negotiated ("critical angle"). We compare our results with other published series in the literature. Results: Eight patients fulfilled the criteria: 5 males (45-66 years). There were three anterior and five posterior circulation aneurysms. Four of the aneurysms were ruptured. The PCOM was traversed in five cases, the ACOM in three cases. The mean diameter of the communicating artery was $1.17 \mathrm{~mm}$. The mean diameter of target arteries was $1.27 \mathrm{~mm}$. The "critical angle" was 72-147 degrees. In all patients, there was satisfactory obliteration of the aneurysm. There were two cases of minor SAH post procedure. Conclusion: Utilizing the Circle of Willis for optimal stent placement in aneurysm remodeling is technically feasible but challenging. This technique can be performed successfully in patients with acute SAH. The procedural risk must be balanced against potential complications such as SAH.
\end{abstract}

RÉSUMÉ: Navigation de prothèses endovasculaires à travers des artères communicantes pour l'embolisation d'anévrismes. Contexte : Le passage d'une prothèse endovasculaire à travers l'hexagone de Willis lors de la mise en place de prothèses endovasculaires pour traiter des anévrismes a été décrit dans de petites séries de cas. Les angles des vaisseaux à traverser et les artères de petite taille sont les défis techniques rencontrés lors de cette manœuvre. Nous présentons notre expérience du traitement des anévrismes au moyen de prothèses endovasculaires lorsque l'hexagone de Willis a été franchi afin de faciliter le déploiement optimal de la prothèse endovasculaire. Méthode : Nous avons revu rétrospectivement les cas traités dans notre institution entre janvier 2009 et juin 2012, chez qui l'hexagone de Willis a été franchi pour faciliter le déploiement optimal de prothèses endovasculaires. Nous avons mesuré le diamètre des artères communicantes franchies, le calibre des artères cibles dans lesquelles une prothèse endovasculaire a été déployée et l'angle le plus aigu négocié («angle critique »). Nous comparons nos résultats à d'autres séries de cas publiés. Résultats : Huit patients rencontraient ce critère, dont 5 étaient des hommes et dont l'âge variait de 45 à 66 ans). Ils étaient porteurs de 3 anévrismes de la circulation antérieure et de 5 anévrismes de la circulation postérieure. Quatre des anévrismes étaient rompus. L'artère communicante postérieure a été franchie chez 5 cas et l'artère communicante antérieure chez 3 cas. Le diamètre moyen de l'artère communicante était de 1,17 mm. Le diamètre moyen des artères cibles était de 1,27 mm. L'« angle critique » était de 72 à 147 degrés. Chez tous les patients, l'anévrisme a été oblitéré de façon satisfaisante. Deux patients ont présenté une HSA mineure après l'intervention. Conclusion : L'utilisation de l'hexagone de Willis pour le déploiement optimal de prothèses endovasculaires dans le remodelage d'anévrismes est faisable techniquement, mais présente des défis. Cette intervention peut être réalisée avec succès chez des patients atteints d'une HSA aiguë. On devrait soupeser le risque associé à la technique et les complications possibles telle une HSA.

Can J Neurol Sci. 2014; 41: 193-199

Endovascular aneurysm treatment has significantly improved over the last three decades. This can be attributed to both advances in experience and technology including catheters, coils, intracranial balloons, and stents. Remodeling of wide-neck aneurysms using intracranial balloons and stents in difficult locations is now possible with a favorable risk profile. In many institutions, stent-assisted coiling is performed in cases where balloon-remodeling is judged to be difficult. There have been many reports in the literature citing novel methods for stent deployment: "Y-stenting", "Horizontal-stent", "X-shape stents" and the "waffle-cone" approach ${ }^{1-4}$. In some cases, conventional approaches to stent-assisted coiling of aneurysms are not

From the Neuroradiology Section - Department of Medical Imaging (MEA, CL, DI, MdS), Division of Neurosurgery - Department of Surgery (HL), The Ottawa Hospital, Ottawa, Ontario, Canada.

Received June 26, 2013. Final Revisions Submitted October 10, 2013 Correspondence to: Cheemun Lum, Neuroradiology Section - Department of Medical Imaging, The Ottawa Hospital, 1053 Carling Avenue Ottawa, Ontario, K1Y 4E9, Canada.Email: chlum@ottawahospital.on.ca. 
possible because of access limitations. Endovascular coiling of aneurysms treated by manipulating catheters and stents across communicating arteries of the Circle of Willis has been described in some case reports and smaller case series for optimal stent placement ${ }^{1,5,6-15}$. This technique requires navigation across acute angles. For example, in order to deploy a horizontal stent across the basilar tip, the angle formed between the posterior communicating artery (PCOM) and posterior cerebral artery first segment (P1) must be negotiated. Similarly, the most acute angle to be navigated for anterior communicating artery (ACOM) stenting is the angle subtended by the supraclinoid internal carotid artery-anterior cerebral artery (ICA-A1) junction. In addition, these techniques require navigation and stent deployment in diminutive recipient arteries. This raises concerns regarding lack of complete stent deployment in these small arteries and possible thromboembolic complications.

We present our experience with treating aneurysms by stent assistance across the communicating arteries of the Circle of Willis to facilitate optimal stent deployment. We analyzed the most acute angle required to navigate endovascular tools and the caliber of arteries crossed by the stent delivery system.

We review the available literature on this relatively new technique of aneurysm treatment to evaluate the technical success rates and associated complications.

\section{Materials AND Methods}

We retrospectively reviewed the cases in our institution from January 2009 to June 2012 in which the Circle of Willis was traversed by a stent delivery microcatheter.

\section{Measurement of arteries and angles}

The decision to traverse the Circle of Willis was made on a case-by-case basis after non-invasive arterial imaging was carefully reviewed. The caliber of the PCOM and ACOM arteries traversed was measured. The target artery was defined as the smallest arterial diameter in which the stent was deployed. We defined the most acute angle that required navigation as the "critical angle". For the PCOM approach, the critical angle was the angle subtended by the PCOM and ipsilateral P1 segment measured in the axial plane (Figure 1). For the ACOM approach, the angle subtended by the supraclinoid internal carotid artery (ICA) and ipsilateral A1 segment in the coronal plane was measured. All the measurements were performed on computed tomography angiogram (CTA) except for one patient in whom a contrast-enhanced MRA was performed. The measurements were performed by a single interventional neuroradiologist with six years advanced neuroimaging training.

\section{Technique}

All procedures were performed on biplane flat panel angiographic system (Siemens AG, Germany) with 3D angiography and road mapping capabilities. Patients were premedicated with dual antiplatelet therapy (Aspirin and Clopidogrel): two patients were loaded during procedure prior to stenting (650mg Aspirin and 300mg Clopidogrel); six patients were started on medication four to five days prior to procedure (81 mg of Aspirin and 75mg mg of Clopidogrel per day). Dual antiplatelet agents were continued for 90 Days. Subsequently, Clopidogrel was discontinued and Aspirin continued indefinitely. All procedures were performed with bilateral femoral access. Systemic heparin was administered during the procedure and monitored with ACT levels to achieve an ACT of $>300$.

We used three different types of open and closed cell design intracranial stents including Enterprise stent (Codman \& Shurtleff, Raynham, MA), Neuroform stent (Boston Scientific/ Target, Fremont, CA) and Solitaire stent (ev3 Inc, Irvine, CA, U.S.A.). The stents were deployed through a Prowler Select plus (Cordis, Neurovascular, Raynham, MA) 2.3 French microcatheter. In the anterior circulation, the micro-wire was advanced distally into the contralateral A2 segments. In the

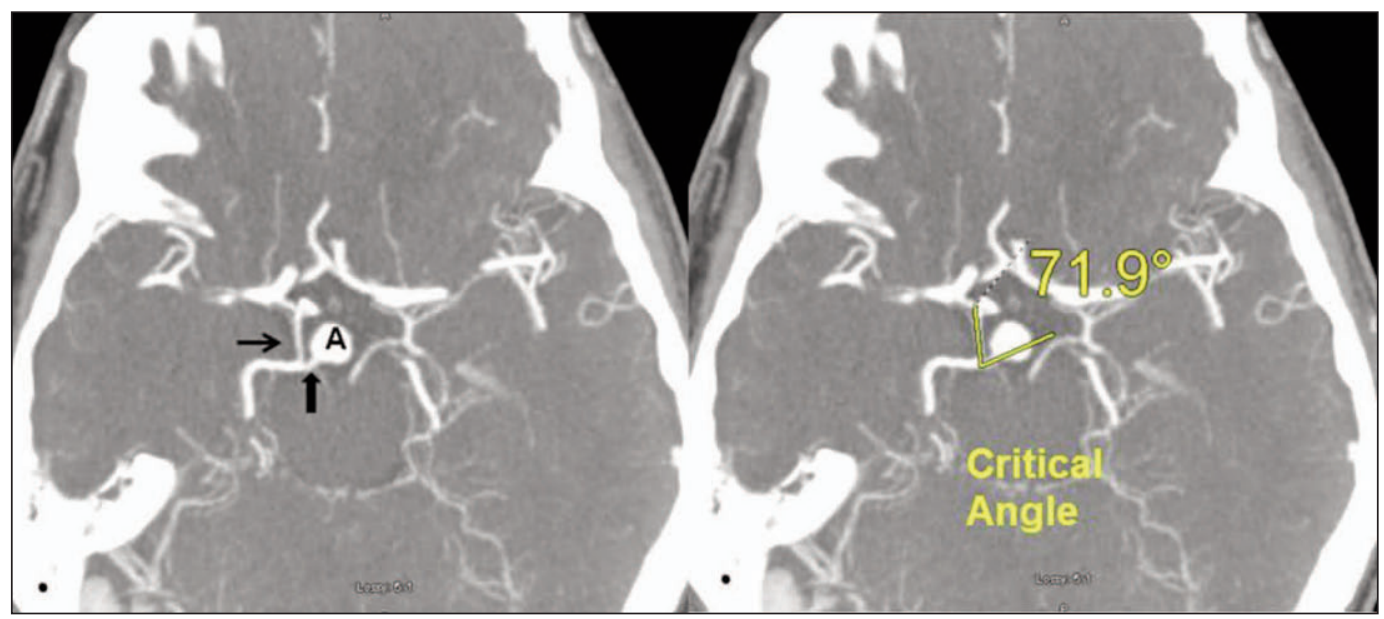

Figure 1: Axial computed tomography angiogram source images demonstrating measurement of critical angle subtended by PCOM (arrow) and P1 (block arrow) in a patient with basilar artery tip aneurysm (A). 
Table 1: Patient demographics, presentation and aneurysm morphology

\begin{tabular}{|c|c|c|c|c|c|c|}
\hline $\begin{array}{l}\text { Case } \\
\text { No }\end{array}$ & Patient & $\begin{array}{l}\text { Initial } \\
\text { SAH }\end{array}$ & $\begin{array}{l}\text { Aneurysm } \\
\text { Location }\end{array}$ & $\begin{array}{l}\text { Aneurysm } \\
\text { Size }(\mathrm{mm})\end{array}$ & $\begin{array}{l}\text { Neck } \\
\text { Size } \\
(\mathrm{mm})\end{array}$ & $\begin{array}{l}\text { Dome/ } \\
\text { Neck } \\
\text { Ratio }\end{array}$ \\
\hline 1 & $65 \mathrm{~F}$ & Yes & $\begin{array}{l}\text { ICA } \\
\text { Terminus }\end{array}$ & $2 \times 1.5$ & 2 & 1 \\
\hline 2 & $45 \mathrm{~F}$ & No & $\begin{array}{l}\text { Basilar } \\
\text { Tip }\end{array}$ & $5 \times 4.3$ & 4 & 1.2 \\
\hline 3 & $55 \mathrm{~F}$ & No & $\begin{array}{l}\text { Basilar } \\
\text { Tip }\end{array}$ & $8 \times 7$ & 6.7 & 1.2 \\
\hline 4 & $55 \mathrm{M}$ & No & $\begin{array}{l}\text { Basilar } \\
\text { Tip }\end{array}$ & $7.2 \times 6.3$ & 6.2 & 1.2 \\
\hline 5 & $54 \mathrm{M}$ & Yes & ACOM & $7.5 \times 5$ & 4.0 & 1.8 \\
\hline 6 & $64 \mathrm{M}$ & Yes & SCA & $8.9 \times 8.5$ & 3.2 & 2.7 \\
\hline 7 & $51 \mathrm{M}$ & Yes & $\begin{array}{l}\text { Basilar } \\
\text { Tip }\end{array}$ & $5.8 \times 2.1$ & 5.1 & 1.1 \\
\hline 8 & $66 \mathrm{M}$ & Yes & A-COM & $7.0 \times 6.5$ & 3.8 & 1.8 \\
\hline
\end{tabular}

$\mathrm{SAH}=$ subarachnoid hemorrhage, ICA = internal carotid artery, $\mathrm{ACOM}=$ anterior communicating artery, $\mathrm{SCA}=$ superior cerebellar artery

posterior communicating artery cases, the micro-wire was advanced to the contralateral P2-P3 segments of posterior cerebral artery in four cases. In one case the microcatheter was placed into the right SCA to treat an SCA aneurysm. In another case, the microcatheter was placed retrograde, via the PCOM, down the basilar artery through the interstices of a previously placed stent in a conventional antegrade fashion.

Coiling of the aneurysms was performed immediately after the stent placement in six out of eight cases. One case was performed in a staged manner where coiling on initial attempt was aborted because of stent migration. The coiling was completed successfully four weeks later through the initially placed stent. One aneurysm was treated by double "telescopic" stents deployed horizontally across the aneurysm neck without using any coils.
At least one follow-up vascular imaging was performed with imaging and clinical follow-up ranging from 6 month to 28 months. Aneurysm obliteration was measured using the Raymond \& Roy scale ${ }^{16}$. The clinical outcome was evaluated by Modified Rankin Scale (mRS).

Medline and PubMed searches were performed through January 2013 to identify relevant articles by using search strings of horizontal stent-assisted coiling, trans-circulation stent assisted coiling, retrograde intracranial stent, aneurysm coiling rupture, and intracranial aneurysm stent from 1999 to 2012. A Google search by using the string "intracranial aneurysm stent" also yielded several other articles. Additional sources were pulled through bibliographies of existing articles. Information derived from articles was used for overall procedure technique, complication analysis and, when available, for specific longterm follow-up metrics. Additional information, available in most publications, was collected regarding complications, technical failure, aneurysm morphology, rupture status and posttreatment occlusion status. The studies describing posterior inferior cerebellar artery aneurysms treatment via contralateral vertebral artery access were excluded.

\section{Results}

We treated eight aneurysms: five males, between 45-66 years-of-age. There were five posterior and three anterior circulation aneurysms: four basilar tip, one ICA terminus, two ACOM and one superior cerebellar artery (SCA) aneurysms treated (Table 1). There were four acutely ruptured, one aneurysm with previous subarachnoid hemorrhage and three unruptured aneurysms.

Three aneurysms were treated with this technique without attempting conventional antegrade stenting. In the other five cases, initial attempt with an antegrade approach for stenting was unsuccessful due to unfavorable anatomy. Stent deployment and coil embolization was technically successful in all cases. In all patients, there was adequate initial obliteration of the aneurysm.

The mean diameter of the communicating arteries was 1.17mm (min: 0.9-max: 1.7). The mean diameter of the target arteries for stent deployment was $1.27 \mathrm{~mm}$ (min: 1.0-max: 1.9). The mean critical angle was 103.8 (min: 72-max: 147). (Table 2).

Table 2: Procedure details and follow-up

\begin{tabular}{c|c|c||c|c|c|c|c}
\hline $\begin{array}{c}\text { Case } \\
\text { No }\end{array}$ & $\begin{array}{c}\text { Size of communicating } \\
\text { artery traversed (mm) }\end{array}$ & $\begin{array}{c}\text { Smallest diameter } \\
\text { target artery(mm) }\end{array}$ & $\begin{array}{c}\text { Critical Angle } \\
(\mathrm{deg})\end{array}$ & $\begin{array}{c}\text { Stent } \\
\text { Follow-up } \\
\text { (months) }\end{array}$ & $\begin{array}{c}\text { Occlusion } \\
\text { Class }\end{array}$ & mRS \\
\hline 1 & $0.9(\mathrm{ACOM})$ & $1.3($ Right A1) & 90 & Enterprise & 24 & Class 1 & 1 \\
\hline 2 & $1.7(\mathrm{PCOM})$ & $1.0($ Left P1) & 98 & Enterprise & 16 & Class 1 & 0 \\
\hline 3 & $1.3(\mathrm{PCOM})$ & $1.2($ Left P1) & 147 & Enterprise & 28 & Class 1 & 0 \\
\hline 4 & $1.3(\mathrm{PCOM})$ & $1.5($ Right P1) & 72 & Neuroform & 14 & Class 3 & 1 \\
\hline 5 & $0.8(\mathrm{ACOM})$ & 1.9 (Right A2) & 116 & Neuroform & 14 & Class 2 & 1 \\
\hline 6 & $1.1(\mathrm{PCOM})$ & $\begin{array}{c}1.2(\text { Right Sup. } \\
\text { Cerebellar Artery) }\end{array}$ & 96 & Solitaire & 19 & Class 3 & 0 \\
\hline 7 & $1.4(\mathrm{PCOM})$ & 1.0 (Right P1) & 119 & Enterprise & 07 & Class 3 & 3 \\
\hline 8 & $0.9(\mathrm{ACOM})$ & 1.1 (Right) A2 & 93 & Solitaire & 06 & Class 1 & 0 \\
\hline
\end{tabular}




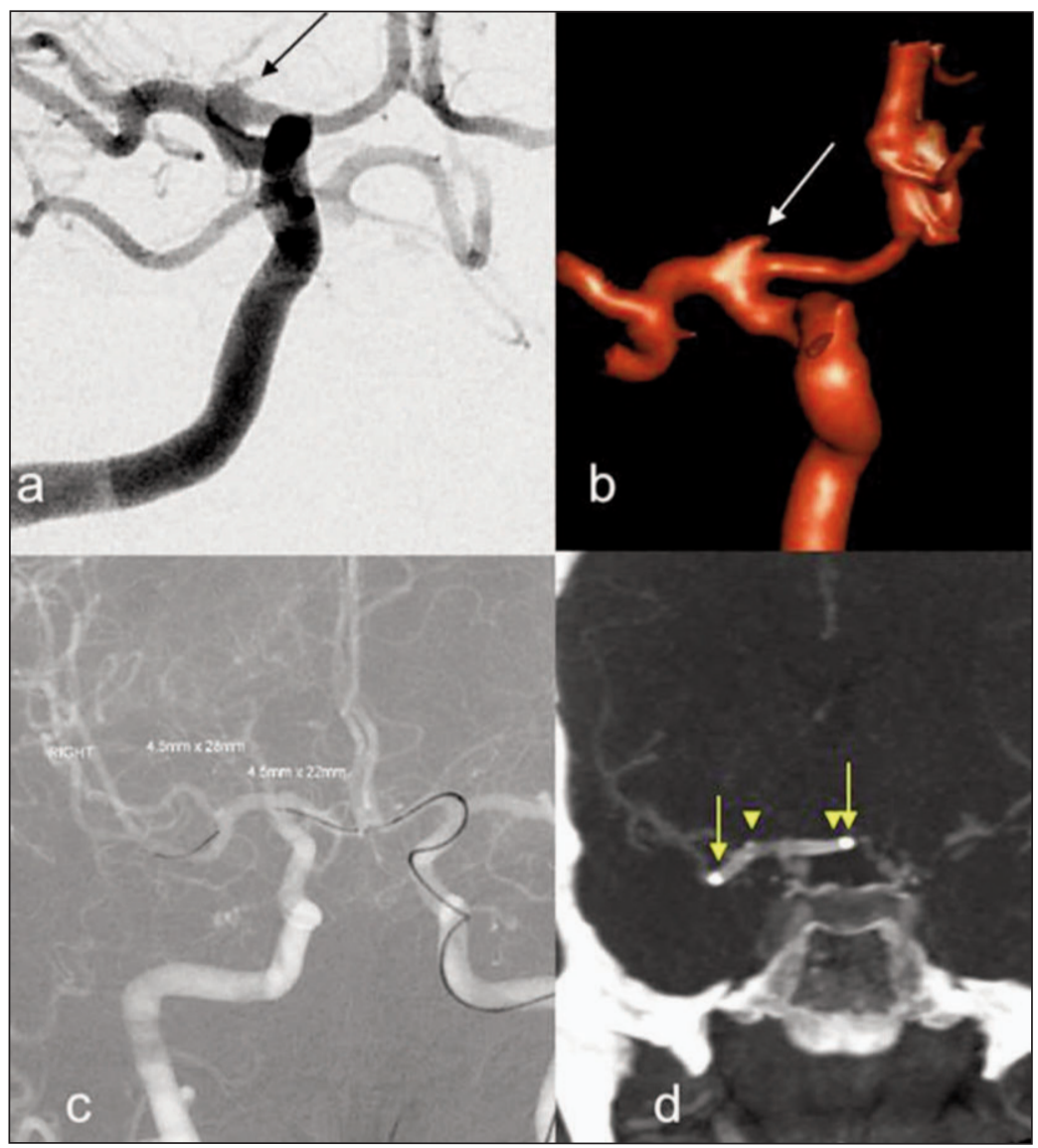

Figure 2: Angiographic images $A \& B$ from Patient 1. A 65 year-old female who presented with subarachnoid hemorrhage from a ruptured right internal carotid artery terminus aneurysm (arrow). C, This $2 \mathrm{~mm}$ sessile aneurysm was approached from the contralateral ICA via the ACOM. D, CTA coronal image demonstrates a double Enterprise stent $(4.5 \times 22 \mathrm{~mm}$; Codman \& Shurtleff, Raynham, MA) construct (arrowhead) was deployed horizontally across the aneurysm neck. The aneurysm was completely obliterated at follow-up with no re-bleed or in-stent stenosis.

There were two cases of small subarachnoid hemorrhage post procedure: both unruptured aneurysms (one anterior and one posterior circulation). These hemorrhages resolved spontaneously on follow-up imaging. One patient developed epistaxis following nasogastric tube placement and subsequently had to be managed with endovascular embolization. One patient had a pelvic extraperitoneal hematoma, which was probably attributed to a difficult femoral puncture while on dual antiplatelet agents and intra-procedural heparin. In one case, a detachable stent was used as a temporary strut however had to be deployed as it could not be retrieved. The stent was deployed with good wall apposition and the patient remained asymptomatic. Overall, there were four major complications in our series. One of our patients (Patient 4) with an unruptured basilar tip aneurysm had a small thalamoperforator stroke with mild sensory changes on discharge. Of the four patients in our series with a discharge $\mathrm{mRS}$ of $>0$, their outcome was felt to be related to their presenting $\mathrm{SAH}$ and not procedure-related.

Follow-up imaging results are shown in Table 2. The minimum follow-up period was six months. One patient had a significant class III recurrence on one-year follow-up and required repeat coiling. Three aneurysms had insignificant recurrences and other four remained completely obliterated on follow-up imaging. No significant in-stent stenosis or occlusions were demonstrated on follow-up imaging.

\section{Case \#1}

We used this technique for the treatment of a small, sessile ruptured $2 \mathrm{~mm}$ carotid terminus/ A1 aneurysm with no neck (Figure 2). The lesion was felt to be technically extremely difficult to treat with surgical clipping and had high risk of rupture with conventional coiling because of its shallow neck. We approached the aneurysm from contralateral ICA via ACOM. A double Enterprise stent (Codman \& Shurtleff, Raynham, MA) construct was deployed horizontally across the aneurysm in "telescopic" fashion for better inflow coverage. The aneurysm was completely obliterated at 24 month follow-up with no rebleed or in-stent stenosis.

\section{Case \#3}

The trans-circulation technique was used to treat a wide-neck basilar tip aneurysm (Figure 3 ). The antegrade stenting in this case was deemed impossible due to a very acute basilar- right P1 angle. The patient had another un-ruptured $20 \mathrm{~mm}$ wide-neck right paraophthalmic aneurysm we previously treated successfully with a flow diverting stent (Pipeline- 


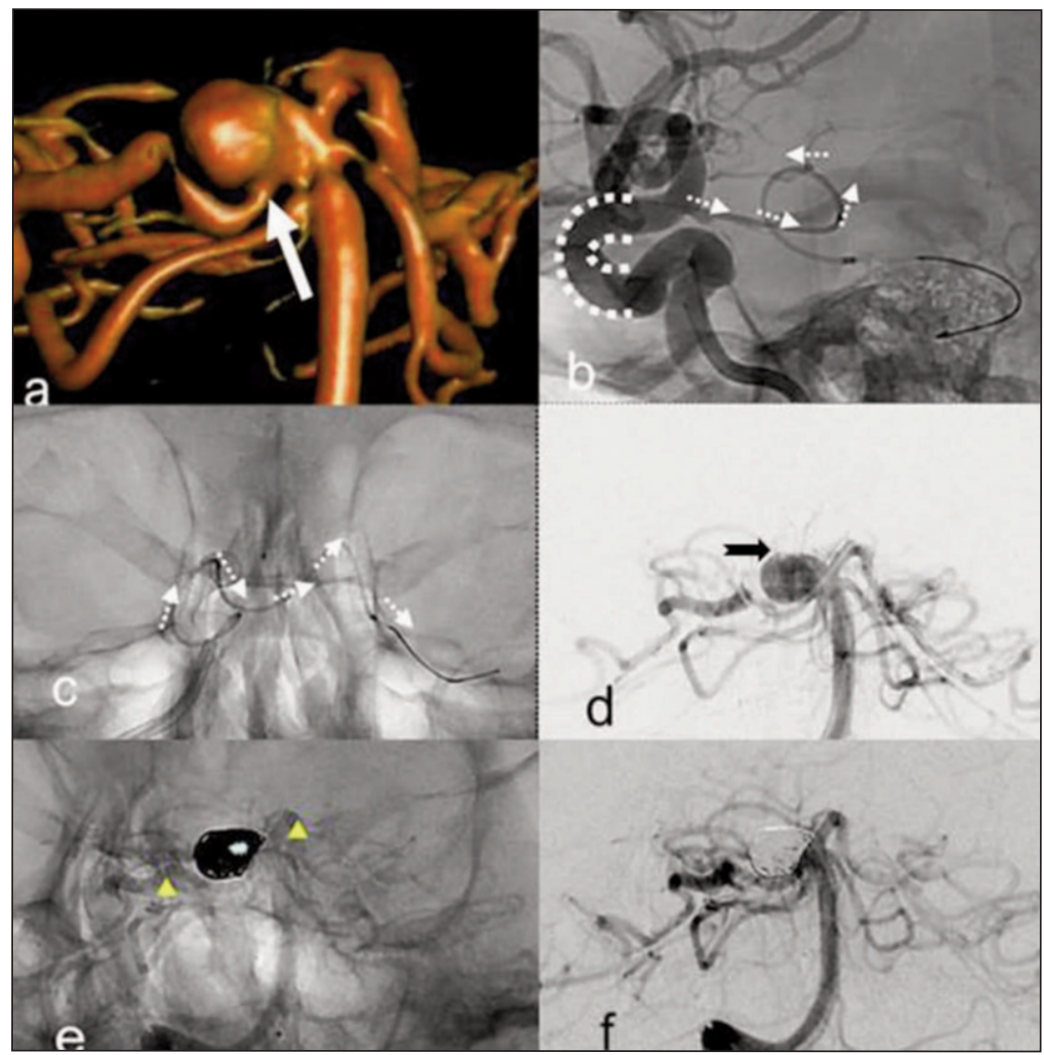

Figure 3: Angiographic images A, from Patient 3. A 55-year-old female with an unruptured wide-neck basilar tip aneurysm (arrow). B. The patient had a previously placed flow-diverting stent (Pipelineev3eurovascular, Irvine, CA) (dotted curved lines) for an unruptured right paraophthalmic aneurysm. Note, the microcatheter access through the PCOM (dotted arrows). C, AP angiogram demonstrates the microcatheter (dotted arrows) manoeuvred through the right PCOM and positioned across the basilar apex with tip in the left PCA. D, A 2nd microcatheter (notched arrow) was jailed in aneurysm via the right vertebral artery. $E$, An Enterprise (arrowheads) was deployed horizontally across the aneurysm neck. F, Coiling was then performed via the jailed catheter to achieve initial class II which improved to class I at follow-up.

ev3eurovascular, Irvine, CA) placed proximal to the PCOM origin. We placed a horizontal stent across the aneurysm neck via right ICA/ PCOM approach with subsequent successful coiling. The aneurysm remains completely obliterated at three years follow-up.

\section{DISCUSSION}

Endovascular treatment of wide-neck aneurysms is technically challenging and may be managed by a variety of approaches ${ }^{17,18}$. Various techniques such as balloon remodeling, stent assisted coiling, "Y" stent construction, and double micro catheter techniques have been used ${ }^{4,19}$. In the case of a terminal aneurysm, it is often difficult or impossible to place a balloon or stent exactly perpendicular to the axis of the aneurysm. One approach has been to place two stents at the arterial termination in a "Y" or " $\mathrm{X}$ " configuration. However, this is not always technically feasible due to the angioarchitecture.

Horizontal (trans-circulation) stent assisted coiling has been described as an alternate option to treat wide-necked aneurysms. This technique involves deployment of a stent across the neck of a terminal aneurysm. The stent is navigated through the Circle of Willis via a communicating artery ${ }^{1}$. A single stent can then be deployed horizontally across the basilar tip, for example, facilitating optimal prevention of coil herniation.

The navigation of stent across challenging angles (critical angles) is necessary for this technique. The mean critical angle in our case series was 103 degrees, though we were able to successfully navigate across an acute angle of less than 75 degrees. We did not have cases in which we failed to negotiate a critical angle of less than 72 degrees. The less acute and more obtuse the angle, the greater the chance of success. We should mention a word of caution: thalamoperforators arise from the P1 segment and therefore care must be taken to avoid impaling a micro wire into a perforator in order to negotiate the acute angle. Park et $\mathrm{l}^{18}$ have described difficulties in catheterizing the PCA from basilar artery due to acute angles and as a result have used the waffle-cone technique.

Manipulating a micro catheter and stent across smaller calibre communicating arteries is another challenge. The mean diameter of PCOM arteries in our cases was $1.36 \mathrm{~mm}$ and for the ACOM arteries was $0.86 \mathrm{~mm}$. We were able to navigate across small communicating arteries with diameters as small as $0.8 \mathrm{~mm}$. In spite of heparinization, it is important to spend as little time as possible with the delivery micro catheter, potentially decreasing flow in the small communicating arteries, in order to prevent thrombosis. In our own experience, we do not have cases in which attempted navigation failed in communicating arteries smaller than $0.8 \mathrm{~mm}$. However, theoretically, complications such as suboptimal stent deployment, dissection and thrombosis may increase by navigating through even smaller calibre arteries.

\section{Literature Review}

A total of 11 articles with 42 patients met inclusion criteria for transcirculation coiling ${ }^{1,5-11,13-15}$. One article was excluded since 
Table 3: Transcirculation stent literature

\begin{tabular}{|c|c|c|c|c|c|c|c|c|c|c|c|}
\hline \multirow[t]{2}{*}{ No. } & \multirow[t]{2}{*}{ Authors } & \multirow{2}{*}{$\begin{array}{l}\mathrm{Pt} \\
\text { No. }\end{array}$} & \multirow{2}{*}{$\begin{array}{l}\text { Initial } \\
\text { SAH }\end{array}$} & \multicolumn{2}{|c|}{ Vessel Crossed } & \multirow{2}{*}{$\begin{array}{l}\text { Permanent } \\
\text { Complications }\end{array}$} & \multirow[t]{2}{*}{ Mortality } & \multirow{2}{*}{$\begin{array}{l}\text { Minimum } \\
\text { Communicating } \\
\text { Artery Size (mm) }\end{array}$} & \multirow{2}{*}{$\begin{array}{l}\text { Critical } \\
\text { Angle } \\
\text { (deg) }\end{array}$} & \multirow{2}{*}{$\begin{array}{l}\text { Successful } \\
\text { Stent } \\
\text { Placement }\end{array}$} & \multirow{2}{*}{$\begin{array}{l}\text { Significant } \\
\text { Recurrence }\end{array}$} \\
\hline & & & & $\mathrm{ACOM}$ & PCOM & & & & & & \\
\hline 1 & Blackburn SL, et al. & 10 & 0 & 0 & 8 & 1 & 1 & 1 & NA & 8 & $0^{*}$ \\
\hline 2 & Current Study & 8 & 5 & 3 & 5 & $\mathbf{0}$ & $\mathbf{0}$ & 1.3 & 72 & 8 & 1 \\
\hline 3 & Albuquerque, et al. & 8 & 0 & 4 & 4 & 0 & 0 & NA & NA & 8 & $0 *$ \\
\hline 4 & Siddiqui, et al & 8 & 1 & 2 & 6 & 1 & 0 & 0.8 & NA & 8 & 1 \\
\hline 5 & Q. Huang, et al & 5 & 5 & 5 & 0 & 0 & 0 & NA & NA & 5 & $1 * *$ \\
\hline 6 & Kelly ME, et al & 5 & 2 & 3 & 2 & 0 & 0 & NA & NA & 5 & 1 \\
\hline 7 & Pride Jr, et al & 3 & 1 & 0 & 3 & 0 & 0 & NA & NA & 3 & 0 \\
\hline 8 & DeWitte T. et al & 1 & 1 & 0 & 1 & 0 & 0 & NA & NA & 1 & 0 \\
\hline 9 & Fitzpatrick et al. & 1 & 1 & 0 & 1 & 0 & 0 & NA & NA & 1 & NA \\
\hline 10 & Benndorf, et al & 1 & 0 & 1 & 0 & 0 & 0 & NA & NA & 1 & NA \\
\hline 11 & Wanke I, et al & 1 & 0 & 0 & 1 & 0 & 0 & NA & NA & 1 & NA \\
\hline 12 & Puri AS et al & 1 & 0 & 1 & 1 & 0 & 0 & NA & NA & 1 & 0 \\
\hline
\end{tabular}

$\mathrm{NA}=$ Not Documented; $* 3$ patients in all studies lost to follow-up; $* *$ Did not specify recurrence in trans-circulation cases or other group. SAH $=$ subarachnoid hemorrhage, $\mathrm{ACOM}=$ anterior communicating artery, $\mathrm{PCOM}=$ posterior communicating artery

the stent was deployed horizontally across the neck of basilar tip aneurysm through an antegrade approach without crossing the communicating arteries ${ }^{20}$. The results are summarized in Table 3. The technique was feasible and successful in 40 of 42 cases (95\%) with more than $90 \%$ initial aneurysm occlusion. Permanent procedure related complications were observed in two out of 42 patients $(4.7 \%)$ with one fatal intra-procedural rupture $^{13}$. The minimum diameter of communicating arteries crossed was $0.8 \mathrm{~mm}$ and stents were successfully placed in arterial diameters as small as $1.1 \mathrm{~mm}$. No prior study has documented the "critical angle" as in our paper. These metrics are potentially useful as a reference for planning future transcirculation stent-assisted coiling procedures. One study mentioned failure to deploy the stent in two cases ${ }^{13}$. Twenty-five percent of aneurysms were treated in the setting of acute or recent subarachnoid hemorrhage. In one of our cases with acute $\mathrm{SAH}$ from an ICA terminus sessile aneurysm, dual telescopic stents were placed horizontally from A1 to M1, a technique which to our knowledge, has not been described. Two patients were reported to have significant recurrence ${ }^{2,5}$.

Blackburn et al have reported the largest series of horizontal stent-assisted coiling with ten patients ${ }^{13}$. The stent placement was successful in eight patients with one case of procedure related mortality. Siddiqui et $a l^{1}$ have described eight cases of horizontal stent assisted coiling across Circle of Willis for treatment of terminal aneurysms. They reported one case of symptomatic in-stent stenosis on 12 months follow-up. Huang et $a l^{5}$ demonstrated the technique in coiling of five anterior circulation aneurysms by placing the stent in the contralateral A2 after crossing the anterior communicating artery. Albuquerque et $a l^{6}$ have described transcirculation as effective pathways for balloon ( $\mathrm{n}=9$ ) and stent-assisted $(\mathrm{n}=8)$ coiling of complex aneurysms. They have quoted a low rate of complications when compared to the natural history of the treated lesion. Fitzpatrick et $a l^{8}$ and Cross $e t a l^{7}$ described this technique for the treatment of a complex basilar terminus aneurysm via the posterior communication artery in their respective case reports.

Two patients in our case series had small new subarachnoid haemorrhages detected on follow-up cross-sectional imaging after the procedure. One of these patients developed hydrocephalus and was managed successfully with a lumbar drainage. The possible mechanisms for these small subarachnoid haemorrhages include traction on small veins secondary to manipulation of these sizeable microcatheters. The other complications of epistaxis and retroperitoneal hematoma were managed without further patient clinical deterioration. We feel the use of concomitant dual antiplatelet agents combined with the technically challenging nature of these procedures contributed to the complications in this series.

Flow-diverting stents have been shown to be effective in the management of some aneurysm which have been difficult to manage by conventional coiling techniques ${ }^{17}$. Most of the aneurysms in our series were terminus aneurysms which would likely necessitate "jailing" one outflow limb with a flowdiverter. Therefore, a thoughtful decision regarding the choice of using the techniques described in our paper or the newer generation flow-diverters is necessary. 


\section{Conclusion}

Utilizing the Circle of Willis for optimal stent placement in aneurysm remodeling is technically feasible but challenging because of navigation in diminutive arteries and across difficult angles. At times, this complex approach is necessary for optimal stent deployment and in some cases is the optimal approach, even in the setting of acute SAH. However, the procedural risk must be balanced against potential complications such as subarachnoid haemorrhages.

\section{REFERENCES}

1. Siddiqui MA, J Bhattacharya J, Lindsay KW, Jenkins S. Horizontal stent-assisted coil embolisation of wide-necked intracranial aneurysms with the Enterprise stent--a case series with early angiographic follow-up. Neuroradiology. 2009;51:411-18.

2. Yang TH, Wong HF, Yang MS, Ou CH, Ho TL. "Waffle cone"technique for intra/extra-aneurysmal stent placement for the treatment of complex and wide-necked bifurcation aneurysm. Interv Neuroradiol. 2008;14 Suppl 2:49-52.

3. Lazzaro MA, Zaidat OO. X-configuration intersecting Enterprise stents for vascular remodeling and assisted coil embolization of a wide neck anterior communicating artery aneurysm. J Neurointervent Surg. 2011;3:348-51.

4. Akgul E, Aksungur E, Balli T, et al. Y-stent-assisted coil embolization of wide-neck intracranial aneurysms. A single center experience. Interv Neuroradiol. 2011;17:36-48.

5. Huang Q, Xu Y, Hong B, Zhao R, Zhao W, Liu J. Stent-assisted embolization of wide-neck anterior communicating artery aneurysms: review of 21 consecutive cases. AJNR Am J Neuroradiol. 2009;30:1502-6.

6. Albuquerque FC, Gonzalez LF, Hu YC, Newman CB, McDougall CG. Transcirculation endovascular treatment of complex cerebral aneurysms: technical considerations and preliminary results. Neurosurgery. 2011;68:820-9; discussion 829-30.

7. Cross DT, 3rd, Moran CJ, Derdeyn CP, Mazumdar A, Rivet D, Chicoine MM. Neuroform stent deployment for treatment of a basilar tip aneurysm via a posterior communicating artery route. AJNR Am J Neuroradiol. 2005;26:2578-81.

8. Fitzpatrick D, Chen M, Meyers PM. Horizontal Neuroform stent deployment for a ruptured basilar terminus aneurysm via the posterior communicating artery. J Vasc Interv Radiol. 2006;17: 1687-91.
9. Benndorf G, Klucznik RP, Meyer D, Strother CM, Mawad ME. "Cross-over" technique for horizontal stenting of an internal carotid bifurcation aneurysm using a new self-expandable stent: technical case report. Neurosurgery. 2006;58:ONS-E172; discussion ONS-E172.

10. Kelly ME, Turner R, Gonugunta V, et al. Stent reconstruction of wide-necked aneurysms across the circle of Willis. Neurosurgery. 2007;61:249-54; discussion 254-5.

11. Wanke I, Gizewski E, Forsting M. Horizontal stent placement plus coiling in a broad-based basilar-tip aneurysm: an alternative to the Y-stent technique. Neuroradiology. 2006;48:817-20.

12. Moret J, Ross IB, Weill A, Piotin M. The retrograde approach: a consideration for the endovascular treatment of aneurysms. AJNR Am J Neuroradiol. 2000;21:262-8.

13. Blackburn SL, Kadkhodayan Y, Shekhtman E, Derdeyn CP, Cross DT, 3rd, Moran CJ. Treatment of basilar tip aneurysms with horizontal PCA to PCA stent-assisted coiling: case series. J Neurointervent Surg. 2013;5:212-16.

14. Puri AS, Erdem E. Unusual intracranial stent navigation through the circle of Willis in a patient with recurrent basilar tip aneurysm during stent-assisted coiling. Interv Neuroradiol. 2009;15:81-6.

15. Pride GL, Jr., Welch B, Novakovic R, et al. Retrograde crossing stent placement strategies at the basilar apex for the treatment of wide necked aneurysms: reconstructive and deconstructive opportunities. J Neurointervent Surg. 2009;1:132-5.

16. Raymond J, Guilbert F, Weill A, et al. Long-term angiographic recurrences after selective endovascular treatment of aneurysms with detachable coils. Stroke. 2003;34:1398-403.

17. O'Kelly CJ, Spears J, Chow M, et al. Canadian experience with the pipeline embolization device for repair of unruptured intracranial aneurysms. AJNR Am J Neuroradiol. 2013;34: 381-7.

18. Park HR, Yoon SM, Shim JJ, Kim SH. Waffle-cone technique using Solitaire AB stent. J Korean Neurosurg Soc. 2012;51:222-6.

19. Baxter BW, Rosso D, Lownie SP. Double microcatheter technique for detachable coil treatment of large, wide-necked intracranial aneurysms. AJNR Am J Neuroradiol. 1998;19:1176-8.

20. Yashar P, Kan PT, Levy EI. Horizontal deployment of an intracranial stent via an antegrade approach for coil embolization of a basilar apex aneurysm: technical note. J Neurointervent Surg. 2011;3: $355-7$. 